\title{
Heating Systems for Small, Scattered and Remote Residential Areas in the Tibetan Plateau
}

\author{
$\mathrm{Ye} \mathrm{Sun}^{1 *}$, Bo Zhao ${ }^{2}$ \\ ${ }^{1}$ School of Liberal Education, Chengdu Jincheng College, Chengdu 611731, China \\ 2 Army Logistics University, Chongqing 401331, China
}

Corresponding Author Email: sunye@scujcc.edu.cn

https://doi.org/10.18280/ijht.390607

Received: 17 July 2021

Accepted: 3 October 2021

\section{Keywords:}

multi-energy complementary smart energy, solar energy storage heat pump, operating energy consumption and costs

\begin{abstract}
This paper targets the heating needs of small, scattered and remote residential areas in the Tibetan Plateau. Considering the severe cold, high altitude, high radiation intensity, long sunshine duration and large temperature difference between day and night, etc. in this region, through the comparative analysis of the performance of heating terminals and heat source systems, it is proposed in this paper that the multi-energy complementary intelligent energy and clean heating approach can effectively reduce operating and maintenance costs, mitigate pollutant emissions and improve the indoor heating environment. Then, with Pagri Town, Shigatse City, Tibet as the pilot area, the multi-energy complementary smart energy and clean heating approach (with solar energy storage heat pump as the heat source + radiators as the heating terminal) was actually applied in the project. Through analysis of the indoor and outdoor temperature changes, electricity consumption and operating costs during the heating period of the pilot project, it is finally concluded that the heating model with solar energy storage heat pump as the heat source + radiators as the heating terminal is a rational choice for the heating systems for small, scattered and remote residential areas in the Tibetan Plateau.
\end{abstract}

\section{INTRODUCTION}

\subsection{Research background}

With an average altitude of over $4,000 \mathrm{~m}$, the Tibetan Plateau is known as the "roof of the world". It is also because of this that the winter in Tibet is long and harsh. The low air temperature seriously affects people's work and life, and thus, heating has become an urgent problem to be solved in winter in Tibet.

However, except in some cities, residential areas in the Tibetan plateau are usually small, scattered and remote, with weak infrastructures. Although these areas are connected to the national grid, there are still problems such as the large power loss and high cost of long-distance transmission and the susceptibility of outdoor power lines to damages. In addition, there are also many problems with the existing heating measures. For example, the distributed heating by electric heaters is convenient, but with a low energy utilization rate and large indoor electrical load, which poses certain risks. For areas with a temperature lower than minus $20^{\circ} \mathrm{C}$, the air source heat pump has such problems as large attenuation of heat generation, significant reduction in the heating efficiency, and high prices and high technical maintenance requirements of low-temperature heat pumps. Although ground source heat pumps are able to achieve stable heat supply with high heating efficiency, it also has problems such as high well cost, restrictions by geological conditions, and decreasing and imbalanced ground temperature after heating. Currently, Tibet is in urgent need of a new heating technology that is safe, stable, environmental-friendly, clean, economic and efficient with low energy supply pressure and reasonable costs.

\subsection{Research significance}

This research is significant in three aspects.

First, it is to respond to the national green and low-carbon development strategy. In recent years, countries around the world have focused their efforts on addressing climate change and reducing the emissions of carbon dioxide and other greenhouse gases in accordance with the Paris Agreement. At the $75^{\text {th }}$ United Nations General Assembly in September 2020, China made a solemn commitment to hit peak carbon emissions by 2030 and achieve carbon neutrality by 2060 . As an ecological barrier for national development, Tibet should be paid more attention to in terms of environmental protection.

Second, it is to solve the practical heating requirements in small, scattered and remote residential areas in Tibet. Due to the limited social support for small, scattered and remote residential areas, traditional heating methods with coal, oil, electricity and gas cannot meet their current heating needs in terms of ecology, economy, stability and safety. It is truly necessary to work out and introduce a safe, stable and efficient clean energy heating technology that adapts to the environment of the residential areas, so as to ensure the normal work and life of the residents there.

Third, it is an innovative exploration to improve the clean energy heating systems in the plateau. Energy harvesting, storage and utilization are important manifestations of the development of human productivity. Considering the abundant solar energy, geothermal resources and water resources in Tibet, it is important to make full use of the natural resources to serve the production and life of the people there. This paper, through comparative analysis of technological, economic and ecological indicators, selected 
the solar energy storage and heat pump system that can better satisfy the heating needs of the small, scattered and remote residential areas in Tibet, and proposed improvement and optimization measures based on engineering practice, which provided a useful reference for the construction of similar types of heating systems in the next steps.

\subsection{Existing research on the heating technology of solar energy storage heat pumps}

Heating with solar energy storage heat pumps involves technologies such as solar photovoltaics, solar thermal power, water source heat pumps, phase change heat storage and system control. Currently, it is a relatively new research subject both at home and abroad.

\subsubsection{Review of overseas research}

In terms of the research on solar energy and water source heat pump system, foreign scholars proposed using the solar heating system as an auxiliary heat source for the heat pump as early as in the 1950s. Jordan and Therkeld [1] proposed integrating the solar thermal collector with the heat pump. Ohanessian et al. [2] used the flat-plate solar collector as the evaporator of the heat pump, marking the beginning of the research on the direct expansion solar-assisted heat pump system. Since then, the heat pump technology has developed and been widely applied in Europe and the United States. The groundwater source heat pump technology is relatively mature in Europe and the United States, and the related research covers a wide range, from the groundwater temperature field, aquifer thermal energy storage and treatment of water quality on the source side to unit efficiency improvement and then to the user side. Tarhouni and Lebbe [3] established a 3D numerical model for the seepage fields of pumping and injection wells by the finite difference method, analyzed the hydraulic field distribution when the artificial reinjection well and the pumping well were running at the same time, and optimized the relationship between the pumping and injection volumes of the re-injection well and the pumping well and the well spacing so that the best balance point could be found to prevent the attenuation of the underground reservoir water storage from causing geological disasters. Kaygusuz and Ayhan [4] proposed a non-direct expansion solar heat pump system, and verified that the hybrid solar heat pump using phase change energy storage materials has the highest efficiency. Obalanlege et al. [5] investigated a hybrid photovoltaic-thermal and heat pump system for solar heating and electricity to supply space heating and electricity at the same time for residences.

\subsubsection{Review of domestic research}

Domestic research on solar + water source heat pump systems started in the late $20^{\text {th }}$ and early $21^{\text {st }}$ centuries. Zheng [6] analyzed the feasibility of the solar + water source heat pump, and calculated the energy consumption and cost that could be saved if it was applied in three cities in China. Yu et al. [7] analyzed and studied various operating conditions for the solar heat pump system, established mathematical models under various operating conditions and determined the operating conditions for the solar heat pump system, which was of significant value to the economics and reliability of the system. Wang et al. [8] conducted a detailed analysis of the planning, layout, floor plan and thermal performance design of 100 solar energy demonstration buildings in the Qinghai-
Tibet Plateau, providing the design basis for the application of solar energy buildings in this region. Wang et al. [9] took an actual project in Inner Mongolia as an example and analyzed the systems with different combinations of solar energy and air source heat pumps so as to find out the solar and air source heat pump heating system suitable for extremely cold areas. Fan et al. [10] analyzed the unique advantages of the solar heating system with air-based energy storage in satisfying the heating needs in the western plateau region in view of the current problems such as large heating demand, lack of natural resources, and difficult maintenance of conventional solar water heating systems in this region, which provided technical support for the improvement of the indoor environment in the western plateau region.

\section{COMPARISON OF THE TECHNICAL AND ECONOMIC PERFORMANCE OF THE HEATING SOURCES COMMONLY USED IN THE PLATEAU}

\subsection{Performance analysis of fan coil units, radiators, and low-temperature floor heating systems}

Heating units commonly used in the plateau include fan coil units, radiators and low-temperature floor heating systems, etc. Specifically, the fan coil units supply heat mainly based on the principle of heat transfer by air convection, and radiators and low-temperature floor heating systems use both naturalconvection heat transfer and radiation heat transfer.

It can be seen that the above heating units operate based on air convection and radiation heat transfer. However, the air in the plateau is thin, with the annual average air pressure being below $652 \mathrm{hPa}$, less than $2 / 3$ of that at the sea level; and the air density is $0.57 \sim 0.89 \mathrm{~kg} / \mathrm{m}^{3}$, which is only $60 \% \sim 70 \%$ of that at the sea level. Heating systems are affected by thermophysical properties, which vary with the altitude. Therefore, a theoretical analysis was performed on the heating performance of these three types of heating units in this paper.

For a fan coil unit, the investigation focused on the convection heating performance. Considering the forced convective heat transfer of the air at a low speed in the fan coil, the correlation for laminar flow heat transfer in a circular tube with constant wall temperature proposed by Sieder and Tate is simplified as follows, with $\operatorname{Pr}=0.7$ :

$$
N \mathrm{u}_{\mathrm{f}}=0.31 \operatorname{Re}_{f}^{0.6}\left(\frac{s_{1}}{s_{2}}\right)^{0.2} \varepsilon_{z}
$$

Then the velocity in the narrowest cross-section is:

$$
\begin{aligned}
& \mathrm{u}=\frac{V}{\sum \mathrm{f}}=\frac{V}{\mathrm{nl}\left(S_{1}-\mathrm{d}\right)} \\
& \operatorname{Re}_{\mathrm{f}}=\frac{\mathrm{du}}{\gamma}=\frac{\mathrm{d} V}{\gamma \mathrm{nl}\left(S_{1}-\mathrm{d}\right)}
\end{aligned}
$$

where, $n, 1, d, S_{1}, S_{2}$ and $\varepsilon_{z}$ are the parameters of the fan coil unit, $\mathrm{V}$ represents the air volume flow, and only $\gamma$ is correlated with the altitude. The attenuation coefficient of the heat transfer coefficient of the fan coil unit changing with the altitude at $20^{\circ} \mathrm{C}$ is shown in the table below: 


\begin{tabular}{cccccccc}
\hline Altitude & 0 & 2000 & 2500 & 3000 & 3500 & 4000 & 4500 \\
\hline Attenuation coefficient & 1 & 0.8629 & 0.8309 & 0.7999 & 0.7691 & 0.7394 & 0.7108 \\
\hline
\end{tabular}

It can be seen that, as the altitude increases, the heat transfer coefficient of the fan coil unit will decrease, and thus the heat output will also decrease with the same power consumption of the heat source. Specifically, when the altitude is above $3500 \mathrm{~m}$, the heat transfer coefficient of the fan coil unit will be $25 \%$ lower than that in the plain area, which means that the heating output has to be increased to achieve the same heating effect.

For the radiation heat transfer of a radiator or a floor heating system, the radiator and other surfaces of the room, or the floor and other walls and floors of the room are considered as the surfaces of two gray bodies in the calculation of the heat transfer between the radiator or floor heating system and the other surfaces in the room.

$$
q_{r}=5.67 \varepsilon_{s}\left[\left(\frac{t_{p}}{100}\right)^{4}+\left(\frac{t_{f}}{100}\right)^{4}\right]
$$

It can be seen that the radiation heat transfer coefficient is not affected by altitude.

For the natural-convection heat transfer of the radiator or floor heating system:

$$
\begin{gathered}
q_{c}=h_{c}\left(t_{p}-t_{n}\right) \\
h_{c}=\left(1-2.22 \times 10^{-5} h\right) 2.627 \\
\times\left(\frac{4.96}{D_{e}}\right)^{0.08} \times 2.67\left(t_{p}-t_{n}\right)^{0.25} \\
D_{e}=4 A_{r} / L_{r}
\end{gathered}
$$

where, tn - the average indoor air temperature;

hc - the natural convection coefficient of the floor or radiator surfaces;

$\mathrm{h}$ - the altitude of the building;

$\mathrm{Ar}$ - the total area of the room;

$\mathrm{Lr}$ - the length of the heating tube.

It can be seen that the natural convection heat transfer of the radiator and the floor heating is affected by the altitude of the building. Its attenuation coefficient is shown in the table below:

\begin{tabular}{cccccccc}
\hline Altitude $(\mathrm{m})$ & 0 & 2000 & 2500 & 3000 & 3500 & 4000 & 4500 \\
\hline $\begin{array}{c}\text { Attenuation } \\
\text { coefficient }\end{array}$ & 1 & 0.88 & 0.86 & 0.83 & 0.80 & 0.78 & 0.75 \\
\hline
\end{tabular}

According to the above theoretical analysis, the heat transfer coefficient of the fan coil unit attenuates with the altitude greater than the natural convection heat transfer coefficient of the radiator or floor heating system. After the radiation heat transfer is considered, the heat attenuation of the radiator or floor heating system is less affected by the altitude than that of the fan coil unit since the radiation heat transfer coefficient does not change with the altitude.

\subsection{Performance analysis of multi-energy complementary smart energy systems, electric hot water boiler systems and oil-fired boiler systems}

\subsubsection{Operating cost}

Assuming that the electricity price is 0.64 yuan $/(\mathrm{kW} \cdot \mathrm{h})$, and the diesel price 6.84 yuan/L, the calculated engineering costs and operating costs of a multi-energy complementary smart energy system, an electric hot water boiler system, and an oilfired boiler system are shown in the following Table 1 .

It can be seen that, although the initial investment cost of the proposed system is high, the operating cost (as low as 10,700 yuan per year) is much lower than those of the traditional energy systems, so it is of great economic value in the long run.

\subsubsection{Analysis of energy efficiency and cost-effectiveness} ratios

Cost-effectiveness ratio $=$ input cost $($ direct construction cost + direct operating cost)/output benefit (heating capacity $/ \mathrm{kwh} \times 8$ hours/day $\times 90$ days/year $\times 20$ years), calculated based on the service life of the system, which is 20 years;

The initial investment mainly includes boilers, heat pump units, circulating water pumps, indoor and outdoor foundations, underground heat exchange system, water intake and reinjection wells, indoor terminal systems, installation and commissioning costs, heat pipe network costs, construction costs, storage capacity and stacking facilities and gas capacity expansion costs, etc. Table 2 analyzes and compares the initial investments and operating costs of several heating systems according to the market prices in 2019.

\subsubsection{Environmental benefit analysis}

Annual standard coal equivalent consumed by each system

The pollutants produced by unit standard coal equivalent (SCE) are calculated based on the current average level of thermal power generation in China. Suppose that the average SCE consumption by power generation of $1 \mathrm{kWh}$ is $0.4040 \mathrm{Kg}$. The SCE consumption is shown in the following Table 3.

It can be seen that the SCE consumption by the proposed multi-energy complementary smart energy system is much lower than that by the traditional oil-fired boiler system or electric hot water boiler system. Specifically, the annual SCE consumption is only $6.74 \mathrm{t}$, only accounting for $1 / 2$ and $1 / 1$ of that of the oil-fired boiler system and electric hot water boiler system, showing its great advantage in energy consumption.

Table 1. Comparative analysis of the systems in terms of economics

\begin{tabular}{cccc}
\hline Type & Multi-energy complementary smart energy system Electric hot water boiler system Oil-fired boiler system \\
\hline Engineering cost $\left(10^{4}\right.$ yuan $)$ & 55.35 & 17.66 & 23.38 \\
Operating cost $\left(10^{4}\right.$ yuan/year $)$ & 1.07 & 2.96 & 6.24 \\
\hline
\end{tabular}

Table 2. Comparative analysis of systems in terms of energy efficiency and cost-effectiveness ratios

\begin{tabular}{cccc}
\hline Type & Multi-energy complementary smart energy system Electric hot water boiler system Oil-fired boiler system \\
\hline Energy efficiency ratio & 2.53 & 0.94 & $/$ \\
Cost-effectiveness ratio & 0.91 & 4.22 & 1.77 \\
\hline
\end{tabular}

Note: the oil-fired boiler system consumes fuel oil, so the energy efficiency ratio was not analyzed for comparison. 
Table 3. Comparison of annual standard coal equivalent consumed by each system

\begin{tabular}{cc}
\hline System type & SCE (t) \\
\hline Multi-energy complementary smart energy system & 6.74 \\
Electric hot water boiler system & 12.23 \\
Oil-fired boiler system & 18.66 \\
\hline
\end{tabular}

2.2.4 Analysis of pollutants produced by each system

The amounts of pollutants produced by each system are summarized as follows [8]:

Table 4. Summary of pollutants produced per unit SCE

\begin{tabular}{ccccc}
\hline Type of pollutant & $\begin{array}{c}\mathrm{SO}_{2} \\
(\mathrm{~kg})\end{array}$ & $\begin{array}{c}\mathrm{NOX} \\
(\mathrm{kg})\end{array}$ & $\begin{array}{c}\mathrm{TSP} \\
(\mathrm{g})\end{array}$ & $\mathrm{CO}_{2}(\mathrm{~kg})$ \\
\hline $\begin{array}{c}\text { Multi-energy complementary } \\
\text { smart energy system }\end{array}$ & 437.80 & 218.90 & 0.004 & 14552.46 \\
$\begin{array}{c}\text { Electric hot water boiler system } \\
\text { Oil-fired boiler system }\end{array}$ & 794.71 & 397.36 & 0.007 & 26416.27 \\
\hline
\end{tabular}

It can be seen from Table 4 that the amounts of the four types of pollutants produced by the proposed multi-energy complementary smart energy system produces are all smaller than those produced by the traditional systems due to the significant reduction in the use of fossil fuels and the energy consumption, fully demonstrating the environmental friendliness of the proposed system.

\subsection{Selection of heat sources for heating systems in the plateau region}

At present, the heating methods widely used in cold regions mainly include centralized or distributed forms, such as gas boilers, wall-hung gas stoves, oil-fired boilers, electric boilers, electric heaters, ground source heat pumps, solar energy and air sources. However, these heating technologies and their thermal efficiency, operating costs, stability and initial investments, etc. are all affected by the environment. Specifically, the gas-fired and oil-fired boilers have relatively low thermal efficiency; the electric boilers require high operating costs; the efficiency of air source heat pumps are seriously affected by the outdoor ambient temperature and the intermittent start and stop at a low temperature affects the heating effect; groundwater source heat pumps are affected by re-injection and water temperature fluctuations; and solar collectors are affected by overheating or frost cracks. Due to these reasons, the current heating systems suffer frequent failures and low heating efficiency, resulting in poor indoor comfort and prominent contradictions between supply and demand. The multi-energy complementary technology has solved the problems of single-energy systems such as poor stability and high operating costs, and its development and utilization results in almost no secondary pollution, making it an effective way to improve clean heating in winter in severely cold and high-altitude areas. It can not only effectively reduce operating and maintenance costs, but also reduce pollutant emissions and improve indoor heating environment.

\section{DESIGN OF THE HEATING SYSTEM SCHEME}

Considering the actual situation of small, scattered and remote residential areas in the plateau, this paper took a residential area at an altitude of $4,350 \mathrm{~m}$ in Pagri Town, Yadong County, Shigatse City as the subject, and designed a multi-energy complementary smart energy system scheme based on solar energy storage heat pumps as the heat source and radiators as the heating terminal.

\subsection{Heating load calculation}

\subsubsection{Design parameters}

Altitude: 4,350m;

Atmospheric pressure in winter: $646 \mathrm{mPa}$;

Average outdoor wind speed in winter: $1.8 \mathrm{~m} / \mathrm{s}$;

Design outdoor dry-bulb temperature in winter: $-12^{\circ} \mathrm{C}$;

Average annual temperature: $2.5^{\circ} \mathrm{C}$, and average temperature in heating season: $-7.3^{\circ} \mathrm{C}$;

Design outdoor relative humidity in winter: $28 \%$;

Percentage of sunshine in winter: $59 \%$;

Maximum depth of frozen ground: $81 \mathrm{~cm}$.

\subsubsection{Design load calculation}

The heat load of the room was obtained by summing up the basic heat consumption of the envelopes, the heat consumptions of cold air infiltration and cold air intrusion and the additional heat consumption.

$$
\begin{aligned}
& Q=\sum Q_{1}+\sum Q_{\mathrm{f}}+\sum Q_{S}=\left(\sum K_{1}\left(\mathrm{t}_{\mathrm{n}}-\mathrm{t}_{1}\right) F_{1}+\sum \mathrm{aK}_{w} F_{k}\right. \\
& +\sum 0.278 \rho_{w} c_{w}\left(t_{n}-t_{w}\right) V N
\end{aligned}
$$

where, Q - total load of the room

$\mathrm{Q}_{1}$ - heat consumption of the envelope enclosure;

$\mathrm{Q}_{\mathrm{f}}$ - heat consumption of cold air infiltration, that is, the heat consumed to heat up the cold air intruding from doors and windows as well as adjacent walls;

$\mathrm{Q}_{\mathrm{s}}$ - heat consumption of cold air intrusion;

$\mathrm{K}_{1}$ - heat transfer coefficient of the building envelopes, including walls, windows, roofs and doors, etc.;

$t_{n}$ - interior design temperature of each room;

$\mathrm{t}_{\mathrm{w}}$ - outdoor design temperature;

$F_{1}$ - area of building envelopes;

a - correction factor;

$\rho_{\mathrm{w}}$ - outdoor air density;

$\mathrm{c}_{\mathrm{w}}$ - specific heat of outdoor air;

$\mathrm{V}$ - room volume;

$\mathrm{N}$ - air change rate;

According to the officially released local statistics and the data collected in this investigation, the calculated heat load in the residential area is $30.2 \mathrm{~kW}$.

\subsection{Design of the solar energy storage and heat pump system}

According to the conclusion obtained in the selection of the heating system in Section 2, and through analysis based on the local natural conditions and heating needs learnt from the investigation as well as the sunshine duration, groundwater resource survey results and heating characteristics, it is proposed that the "seasonal heat storage + short-term heat storage + groundwater well heat transfer" technologies be adopted and that the solar energy storage and heat pump system in the multi-energy complementary smart energy system be selected as the pilot system. During the heating season, the system uses the solar collector system as the main heat source and the hot water storage tanks as the secondary heat source. During the period when the solar energy can be 
utilized, the solar radiation heat can be collected as much as possible through the collector plates, so that it can be used along with the passive heating design of the residential houses to maintain the room temperature and hot water demand at the same time, and in addition, the heat energy required for the heating period is stored in the hot water storage tanks in the form of hot water for a short term; during the heating period, the heat storage system is preferentially used as the main heat source for the regenerative heat pump units, and when the heat storage system cannot meet the needs of the heat pump units, the groundwater source and units will be started for direct heating. Under special conditions, the heat storage system and the underground heat transfer wells will operate concurrently to complement and back each other up. In extreme conditions, the backup generator will be used to assist heating, and technologies such as heat collection, storage and auxiliary heating, heat exchange and waste heat resource utilization will be used comprehensively to ensure heating safety. In the nonheating season, the system will store heat in the hot water storage tanks through the heat transfer module, which will heat the surrounding rock and soil of the water tanks and increase the ground temperature, realizing geothermal recovery and seasonal heat storage. Table 5 below shows the system design parameters.

Table 5. System design parameters

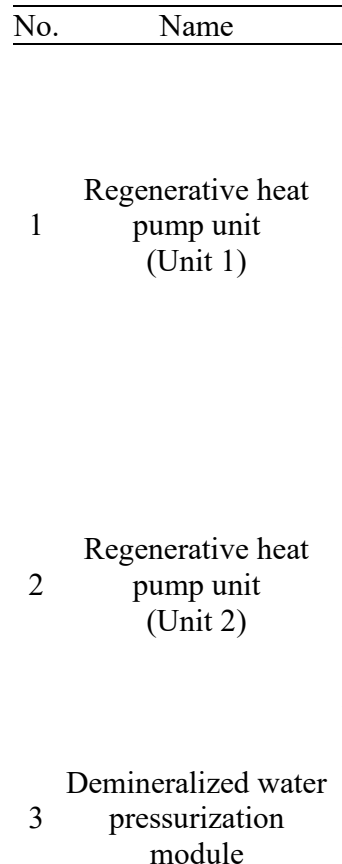
module

4 Heat transfer module

\section{Main parameters \\ Heating capacity: $1500 \mathrm{KW}$ \\ Electric power: $511 \mathrm{KW}$ \\ Circulating water volume: $86 \mathrm{~m}^{3} / \mathrm{h}$}

Inlet and outlet water temperature at the load side: $55^{\circ} \mathrm{C} / 70^{\circ} \mathrm{C}$

Inlet and outlet water temperature at the heat source: $10 / 5^{\circ} \mathrm{C}$

Features of the unit: adopting integrated design, with built-in hydraulic module, power module, control

Each 1 module and antifreeze module, falling film evaporator, stepless capacity adjustment, overload, overvoltage and undervoltage protection, built-in wed (EKI) control module, platform data access, custom programs for upgrade, fault warning, data collection, remote control, maintenance prompt and double data encryption and other functions.

Heating capacity: $1020 \mathrm{KW}$

Electric power: $354.5 \mathrm{KW}$

Circulating water volume: $60 \mathrm{~m}^{3} / \mathrm{h}$

Inlet and outlet water temperature at the load side: $55^{\circ} \mathrm{C} / 70^{\circ} \mathrm{C}$

Inlet and outlet water temperature at the heat source: $10 / 5^{\circ} \mathrm{C}$

Features of the unit: adopting integrated design, with built-in hydraulic module, power module, control

Each 1

module and antifreeze module, falling film evaporator, stepless capacity adjustment, overload, overvoltage and undervoltage protection, built-in wed (EKI) control module, platform data access, custom programs for upgrade, fault warning, data collection, remote control, maintenance prompt and double data encryption and other functions.

Makeup water pressurization device: make-up pump: $\mathrm{Q}=3 \mathrm{~m}^{3} / \mathrm{h} ; \mathrm{H}=35 \mathrm{~m}$

Total volume of the pressurization tank: $2.5 \mathrm{~m}^{3}$

Each 1

Rated flow of the circulating pump: $154 \mathrm{~m}^{3} / \mathrm{h}$;

Rated head: $27 \mathrm{mH}_{2} \mathrm{O}$;

Motor power: $22 \mathrm{~kW}$

Rated flow of the circulating pump: $354 \mathrm{~m}^{3} / \mathrm{h}$;

Rated head: $13.5 \mathrm{mH}_{2} \mathrm{O}$;

Motor power: $22 \mathrm{~kW}$

Pressurization tank: effective adjustment volume $2 \mathrm{~m}^{3}$

Plate heat exchanger: heat exchange of $1715 \mathrm{kw}$

A $5030 \times 2270$ flat plate micro-solar collector, using the blue film absorbing coating technology, with a solar

5 Micro-solar collector absorption rate of $95 \% \pm 2 \%$ and an emissivity of $5 \% \pm 2 \%$. It can bear a pressure of up to $1.0 \mathrm{mpa}$ and has anti-Each 212 freeze and anti-hail protection.

6 Underground water intake well

Diameter: $\varphi 800$, depth: $60 \mathrm{~m}$

Each 6

Heat storage water tank

Pressure tanks, with an effective volume of $100 \mathrm{~m}^{3} / \mathrm{each}$

$\mathrm{m}^{3} 600$

8 Make-up water tank Special water filter

9 for water source heat pump

10 Elevated expansion tank
Each 1

Water flow rate: $60 \mathrm{~m}^{3} / \mathrm{h}$

Each 2

Effective volume: $2 \mathrm{~m}^{3}$

\subsection{Control system and operation mode of the solar energy storage heat pumps}

The solar energy and water source heat pump assisted heating system uses both solar energy and water source heat pumps as the direct heat sources. The solar collector system is connected in series, parallel or both with the water source heat pump units to meet the heat load of the buildings. The series system have two modes - return water heated at the solar heating terminal and water supply by heat pumps. The parallel system adopts the parallel operation of solar energy and water source heat pumps: when only solar energy is sufficient meet the heating demand, the water source heat pump system is turned off; when the solar collector system is only able to provide part of the heat load, the solar collector system and the water source heat pumps will run at the same time; and when 
the temperature of the output water through the heat storage of the solar energy storage system cannot meet the heating temperature requirement, the solar collector system will be turned off, and the water source heat pumps will operate alone. The hybrid system combines the above two modes of operation and also offers an additional operation mode: when the solar collector system cannot provide the heating temperature, the solar collector system and the water source heat pumps will operate in series until the solar energy storage device can no longer supply heat, at which time the water source heat pumps will operate alone.

Since the research focuses on the winter heating for residential areas in the cold plateau region, which has a large and long-term heating demand but is an area with sufficient solar energy resources and long duration of sunshine, the system should aim to maximize the solar fraction and the energy efficiency of water source heat pumps. The system is managed by a smart energy management and control platform (Figure 1). The unit is equipped with an information acquisition module, a computing module and a communication module and connected to the smart energy management and control platform through the wide-area
Internet to realize the computation, storage, processing and sharing functions and provide remote management, operational analysis, fault alarm, maintenance warning, operational monitoring and double data encryption of heat pump units. Some of the specific functions are as follows:

Remote monitoring: 24-hour monitoring and recording of system operation data such as the number of equipment in operation, equipment operation status, equipment temperature, system medium pressure and temperature and heating room temperature;

Remote control: either local control or remote control can be selected. In the remote control mode, the system can be remotely switched, started and stopped in case of emergency;

Fault warning: the smart management and control system can compare and analyze the monitored data of equipment operation with the data intervals of normal operation. If any fluctuation or abnormality is found in operating data, immediate local/remote warning will be given. The warning information can be sent to the computers or mobile phones designated by the equipment management personnel to remind the maintenance personnel to conduct patrol inspection or maintenance.

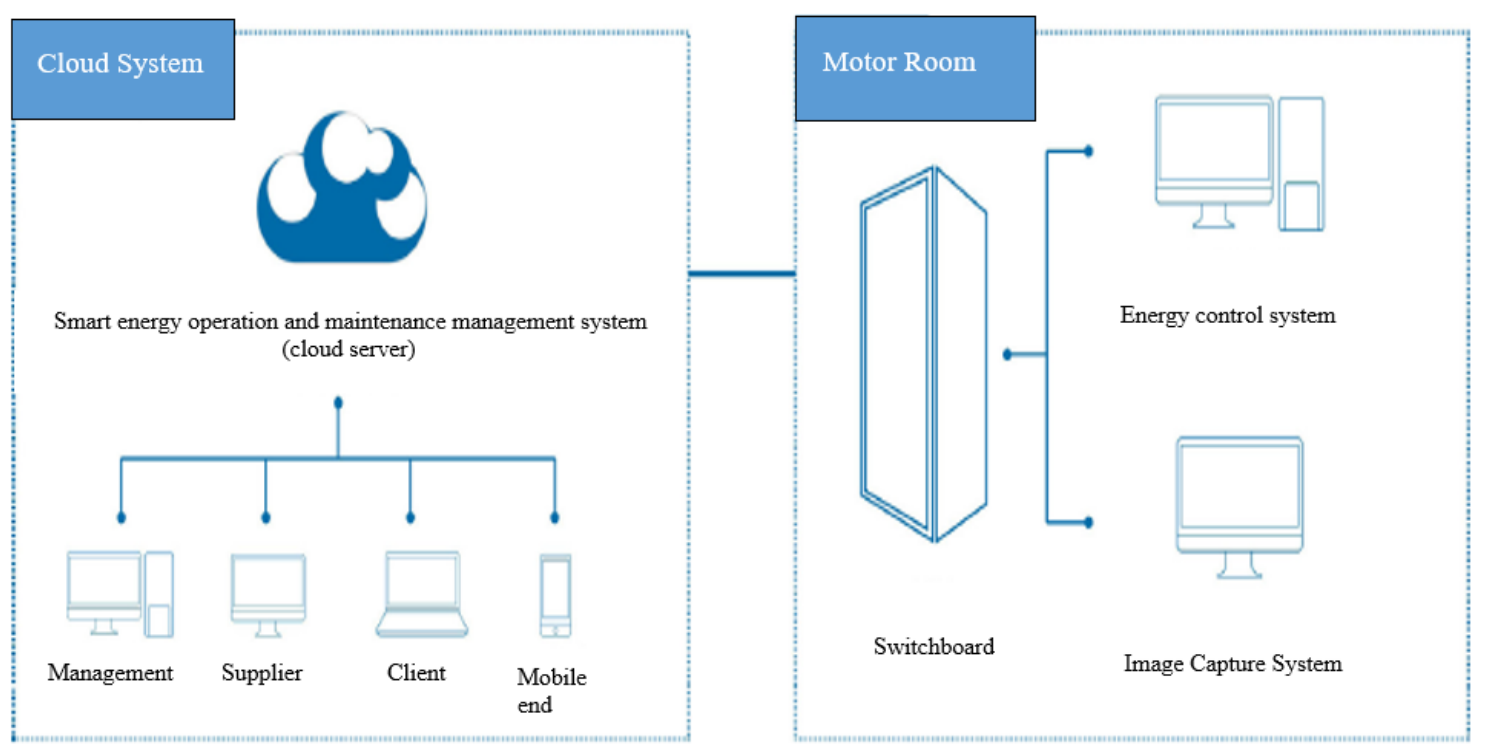

Figure 1. Control logic of the smart energy management and control platform

\section{CASE STUDY}

\subsection{Project profile}

According to the design scheme, the project started construction in June 2019, and was completed and officially started heating in September of the same year. According to the actual situation on site, the system was actually equipped with a regenerative heat pump unit with a rated heating capacity of $29.34 \mathrm{kw}, 8$ underground wells with a depth of $50 \mathrm{~m}$, flat plate collectors with an area of $50 \mathrm{~m}^{2}$, hot water storage tanks with a volume of $15 \mathrm{~m}^{3}$, and a $30 \mathrm{kw}$ standby generator set. The direct investment in the heating system was about 970,000 yuan. In the heating season after installation, the unit operated stably and showed high energy efficiency.

\subsection{Data analysis}

Based on the operation data automatically recorded by the solar energy storage and heat pump system in the pilot area, the operating conditions and energy efficiency data of the heating system were analyzed, with the results shown in Figure 2 and Figure 3.

It can be seen from the table that, during the heating period, the heating capacity of the heat pump unit changed in the opposite direction with the solar heating capacity. The heating capacity of the heat pump unit increased first and then decreased and reached the maximum value $(394305.79 \mathrm{KWh})$ in January, the coldest month of the year. The electricity consumption by the heat pump unit changed in the same trend with the heating capacity of the unit. The power consumption was the largest $(98320.64 \mathrm{KWh})$ in the coldest month. The heating performance coefficient COP of the heat pump unit is determined by the heating capacity and power consumption of the unit. The monthly average COP of the unit reached the maximum value (3.90) in January, the coldest month, and the average value in the heating season was above 3.5 , indicating that the unit operated relatively stably. 


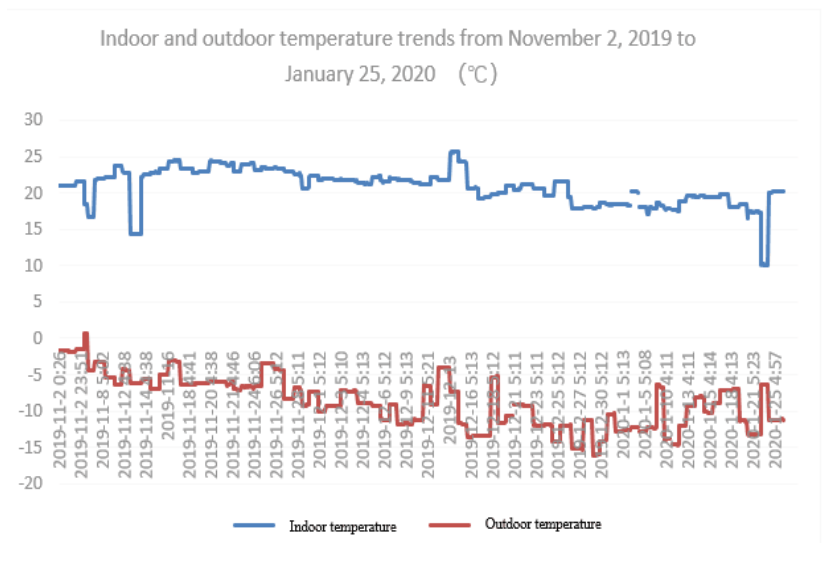

Figure 2. Analysis of the heating temperature trend of the pilot project in the past three months

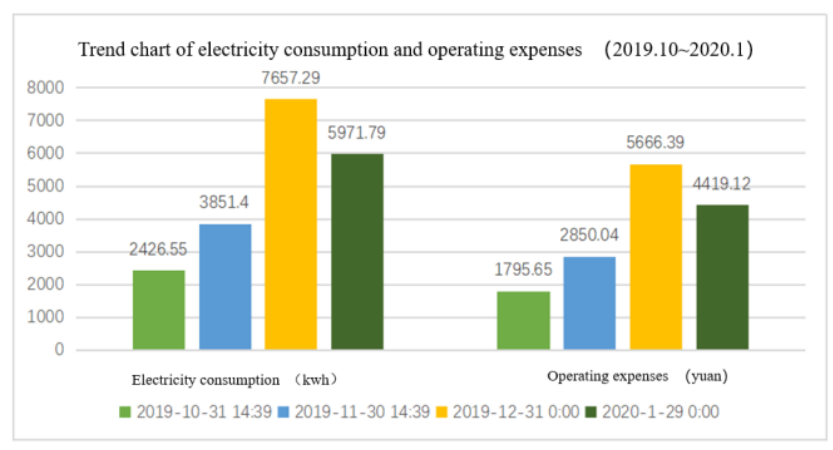

Figure 3. Electricity and operating cost trends of the pilot project

\section{CONCLUSION AND PROSPECT}

Considering the energy and climate characteristics and heating conditions of the plateau region, this paper took a residential area at an altitude of $4,350 \mathrm{~m}$ in Pagri Town, Yadong County, Shigatse City as the subject, and compared the heating attenuation coefficient of heating terminals and the engineering costs, operating costs, and environmental benefits of heating systems based on the local meteorological data. Finally, it selected a multi-energy complementary smart energy system consisting of a solar energy storage and heat pump system as the heat source and radiators as the terminal as the pilot project in this region. Based on the test data, the following conclusions were drawn:

Compared with the conventional heating systems, such as oil-fired boiler systems and electric hot-water boiler systems, etc., the solar energy storage and heat pump system requires higher initial investment, but it takes lower operating costs and operates in an efficient and stable manner, showing an obvious advantage in the whole life cycle cost. Therefore, it is a rational choice for heating in severely cold and high-altitude areas of Tibet.

\section{REFERENCES}

[1] Jordan, R.C., Threlkeld, J.L. (1954). Design and economics of solar energy heat pump system. Heat., Piping Air Cond.; (United States), 26: 122-130.

[2] Ohanessian, P., Charter, W.W.S., Taylor, L.E. (1978). Computer simulation of a solar boosted air source heat pump. Sun: Mankind's Future Source of Energy, 12: 1483-1486. https://doi.org/10.1016/B978-1-4832-8407$1.50284-1$

[3] Tarhouni, J., Lebbe, L. (1996). Optimization of recharge and pumping rates by means of an inverse 3D model. Water Resources Management, 10(5): 355-371. https://doi.org/10.1016/B978-1-4832-8407-1.50284-1

[4] Kaygusuz, K.A.M.İ.L., Ayhan, T. (1999). Experimental and theoretical investigation of combined solar heat pump system for residential heating. Energy Conversion and Management, 40(13): 1377-1396. https://doi.org/10.1016/S0196-8904(99)00026-6

[5] Obalanlege, M.A., Mahmoudi, Y., Douglas, R., Ebrahimnia-Bajestan, E., Davidson, J., Bailie, D. (2020). Performance assessment of a hybrid photovoltaicthermal and heat pump system for solar heating and electricity. Renewable Energy, 148: 558-572. https://doi.org/10.1016/j.renene.2019.10.061

[6] Zheng, R.D. (2000). Feasibility and benefit analysis of solar heating for water source heat pump. Proceedings of the National HVAC Refrigeration 2000 Academic Annual Conference, pp. 473-476.

[7] Yu, Y.S., Ma, Z.L., Lian, L.M. (2004). Simulation study on operating condition of solar heat pump system. Fluid Machinery, 32(5): 65-69. https://doi.org/10.3969/j.issn.1005-0329.2004.05.019

[8] Wang, D.J., Liu, Y.F., Liu, J.P. (2015). Experimental study on the heating performance of passive solar energy buildings in the Qinghai-Tibet Plateau. Architectural Science Research in Sichuan, 41: 269-274. https://doi.org/10.3969/j.issn.1008-1933.2015.02.070

[9] Wang, X.T., Tang, R.N., He, B. (2018). Design and application of solar combined air source heat pump heating system in severe cold areas. Building Energy Conservation, 46: 126-130 https://doi.org/10.3969/j.issn.1673-7237.2018.09.027

[10] Fan, R., Li, Y., Dong, X. (2018) Analysis of air energy storage solar heating system in high altitude area in western China. Building Science, 34: 121-129. https://doi.org/10.13614/j.cnki.11-1962/tu.2018.12.20 